\title{
A EDUCAÇÃO ESCOLAR NO BRASIL: O PÚBLICO E O PRIVADO
}

SCHOOL EDUCATION IN BRAZIL:THE PUBLIC AND PRIVATE SPHERES

Carlos Roberto Jamil Cury ${ }^{1}$

Resumo Este artigo tem por fim esclarecer alguns pontos significativos para a compreensão da relação público-privado na educação e no ensino. Para tanto, buscou-se no ordenamento jurídico atual - sem deixar de referir-se ao do passado - compreender como tal relação se coloca. Daí o entendimento do significado da educação como serviço público e da necessidade das instituições privadas terem a autorização do poder público para seu funcionamento. O estudo pretendeu criar, tanto quanto possível, um espaço para comparação com conceitos iguais ou semelhantes na área da saúde.

Palavras-chave ensino público e ensino privado; ensino no ordenamento jurídico; a educação como serviço público.
Abstract This article intends to address a few important issues for comprehending the public/private relation in education and teaching. To do so, the current law was investigated and this relation assessed. This revealed an understanding of education as a public service, which would, thus, explain the authorization required from private schools. The article also provides a comparison with similar notions in the area of health.

Keywords public education and private education; education as seen by law; education as a public service. 


\section{Introdução}

A educação escolar no Brasil, presente nos sistemas de ensino em suas redes públicas e privadas, para efeito de seu entendimento mais geral, deve remeter-se à organização da educação nacional tal como a estabelece o ordenamento jurídico.

Contudo, é preciso assinalar, desde logo, o comparecimento da Universidade na Constituição Federal de 1988 como instituição dotada de 'autonomia' para cuja identidade a indissociabilidade entre ensino, pesquisa e extensão torna-se essencial (artigo 207).

Isto posto, nossas constituições sempre reconheceram a organização da educação nacional em torno da distinção entre dois grandes 'gêneros' de escola: a livre e a regular.

A escola livre está fora do âmbito da Lei de Diretrizes e Bases da Educação Nacional (LDB), de 1996. É o caso, por exemplo, de escolas de línguas, de natação, de culinária, de técnicas de computação, entre tantas outras. As escolas livres apóiam-se no artigo 5, inciso XIII, da Constituição. Os certificados que elas emitem não possuem valor oficial. Mas podem ter valor de mercado. Nesse sentido é conseqüente à legislação fazer a distinção entre educação e educação 'escolar'.

O reconhecimento oficial de um certificado ou diploma, emitido por uma instituição escolar, com validade nacional ou regional, é dado apenas por órgãos públicos ou por quem se veja por eles autorizado e avaliado (artigo 209). Esse é o caso da escola regular que se submete ao conjunto das diretrizes e bases da educação nacional (LDB, artigo 1, parágrafo $1^{\circ}$ ), inclusive para o reconhecimento formal de seus atos e expedição de diplomas e certificados.

Por sua vez, a educação escolar regular, enquanto gênero, divide-se em suas grandes 'espécies': as públicas e as privadas.

A Constituição Federal, como posto no artigo 206, inciso III, reconhece a 'coexistência' entre estabelecimentos de ensino públicos e privados. Esse termo - coexistência -, como se verá, implica uma alteração significativa em nossa evolução histórica. A coexistência deve estar sob a lei, sob a regra (em latim regula), daí a denominação de regulares. E a regra é tanto a Constituição, enquanto Lei Maior, quanto as leis específicas da educação, como é o caso, entre outras, da LDB, da lei do Plano Nacional de Educação $\left(\mathrm{n}^{\circ}\right.$ 10.172/01) e até mesmo dos pareceres e resoluções dos órgãos normativos dos sistemas (Conselhos de Educação).

As escolas públicas são oficiais por sua natureza jurídica e por seu caráter de serviço público próprio. Ligadas ao Estado, elas são 'dever' dos governos que o ocupam e tem nele sua autoridade, dentro do regime democrático e republicano. Mas esse dever não se funda em si próprio. Seu 
fundamento é o direito do estudante enquanto cidadão. Porque o estudante como cidadão tem esse direito é que o Estado se obriga a fornecer a educação escolar, satisfazendo um princípio maior que atinge a todos².

A escola pública, por sua vez, dado nosso regime federativo composto por União, Estados, Distrito Federal e municípios, subdivide-se, de acordo com os respectivos sistemas administrativos de ensino, em municipal, estadual, distrital e federal.

No caso das escolas particulares, a sua presença na organização da educação nacional foi variável, embora todas as constituições brasileiras as tenham reconhecido sob a figura da 'liberdade de ensino', de acordo com o artigo 209 da Constituição.

Mas a liberdade de ensino, obedecendo à legislação educacional, tem no Estado seu poder fundante, concedente ou autorizatório da educação escolar. Isto conduziu a que a legislação brasileira impusesse um certo controle da liberdade de ensino, a depender de conjunturas históricas específicas. No caso dos regimes autoritários, por exemplo, ela também sofreu restrições no que concerne à liberdade de expressão, mantidas as reservas gerais quanto à sua expansão.

\section{Alterações recentes}

A legislação ganhou novos contornos com a Constituição de 1988, através dos dispositivos relativos à coexistência institucional, lucratividade, autorização e avaliação. A avaliação, sobretudo da maneira como foi inserida na LDB, muda o foco da qualidade de todos os níveis e etapas do ensino da entrada do processo (autorização) para o produto final (avaliação em vista do recredenciamento).

A atual formulação legal diferencia-se um pouco de legislações passadas em que a educação escolar privada era uma 'concessão' do Estado. A noção de coexistência institucional (artigo 206, inciso III) acabou por deslocar a categoria concessão para a categoria "autorização e avaliação de qualidade" (artigo 209). A LDB, em seu artigo 7, adicionará outra condição: a "capacidade de autofinanciamento".

Isto quer dizer que há pressupostos para a inserção da iniciativa privada na educação escolar regular e condições para seu estabelecimento. Submetendo-se aos processos de autorização e de avaliação, devendo ser autosustentável, ela presta um serviço de interesse público por natureza (isto é, o direito ao saber), ainda que por meio do sistema contratual de mercado (iniciativa privada). Conformada à legislação educacional, seus atos tornamse oficializados. Submetida aos parâmetros legais necessários para que seus atos e diplomas possuam a mesma validade dos emanados de escolas oficiais, 
ela deve respeitar também os artigos 1 , parágrafo $1^{\circ}, 3$, inciso III, e 20 da LDB, entre outros.

Resta agora analisar o estatuto da autorização e sua relação com a noção de 'serviço público'.

\section{Uma alteração significativa: da concessão à autorização}

Os juristas estudiosos do Direito Administrativo fazem uma distinção entre serviços públicos próprios e impróprios.

“(...) serviços públicos próprios são aqueles que, atendendo a necessidades coletivas, o Estado assume como seus e os executa diretamente (por meio de seus agentes) ou indiretamente (por meio de concessionários ou permissionários). $\mathrm{E}$ os serviços públicos impróprios são os que, embora atendendo também a necessidades coletivas, como os anteriores, não são assumidos nem executados pelo Estado, direta ou indiretamente, mas apenas por ele autorizados, regulamentados e fiscalizados; eles recebem impropriamente o nome de serviços públicos porque atendem a necessidades de interesse geral; vale dizer que, por serem atividades privadas, são exercidas por particulares, mas, por atenderem a necessidades coletivas, dependem de autorização do Poder Público, sendo por ele regulamentados e fiscalizados; ou seja, estão sujeitos a maior ingerência do poder de polícia do Estado" (Di Pietro, 2004, p. 88).

No fundo, os serviços públicos se dividiriam em duas espécies: os próprios e os impróprios. Os próprios são do Estado, mas neles caberia, porém, importante distinção: os indelegáveis, que, por serem exclusivos do Estado, não comportam delegação aos particulares (ver CF/88, artigos 20 e 21), e os delegáveis, que, ainda que privativos do Estado, podem ser delegados caso se submetam aos critérios de concessão ou de permissão. A lei federal de concessões e permissões ( $\left.n^{\circ} 8.987 / 95\right)$, não regula expressamente em seu teor a figura da autorização. Já os serviços impróprios, além de delegáveis a particulares, obedecem aos ditames autorizatórios, normativos, fiscalizatórios e avaliadores do poder de Estado.

A educação escolar não caberia como uma luva no estatuto dos serviços públicos impróprios?

À primeira vista, não resta dúvida.

Mas a educação escolar enquanto serviço público por excelência não seria uma atribuição própria do Estado? 


\section{Educação escolar: um serviço público de Estado}

Se a educação escolar implica a cidadania e seu exercício consciente; se ela qualifica para o mundo do trabalho; se é, ao menos na etapa do ensino fundamental, gratuita e obrigatória, e progressivamente obrigatória no ensino médio; se a educação infantil é também dever do Estado; se ela visa ao pleno desenvolvimento da pessoa, como retirá-la dos objetivos fundamentais da República do Brasil postos no artigo 3 da Constituição? Como não tê-la como serviço público de caráter próprio?

Em seu Curso de direito constitucional positivo, o constitucionalista José Afonso da Silva, afirma:

“(...) a educação, como processo de reconstrução da experiência, é um atributo da pessoa humana e, por isso, tem que ser comum a todos. É essa a concepção que a Constituição agasalha nos arts. 205 a 214, quando declara que ela é um direito de todos e um dever do Estado. Tal concepção importa (...) em elevar a educação à categoria de serviço público essencial que ao Poder Público impende possibilitar a todos" (Silva, 1999, p. 397).

Então como entender a passagem da concessão e da permissão para o estatuto da autorização?

Segundo Celso Antônio Bandeira de Mello (1996, p. 256), autorização "é o ato unilateral pelo qual a Administração, discricionariamente, faculta o exercício de atividade material, tendo, como regra, o caráter precário".

Assim, de acordo com Oswaldo Bandeira de Mello, as escolas particulares são

“(...) pessoas jurídicas de direito privado, que agem em nome e por conta própria, paralelamente ao Estado, no exercício de atividades havidas como públicas, que legalmente lhes são facultadas, e com poder de império específico, atribuído pelo Estado para consecução de tais cometimentos, coadjuvantes de sua ação" (Bandeira de Mello, 1969, p. 556).

O caso das instituições privadas voltadas para a educação encaixa-se na ressalva do parágrafo único do artigo 170 da Constituição. “É assegurado a todos o livre exercício de qualquer atividade econômica, independentemente de autorização de órgão públicos, salvo nos casos previstos em lei" (Brasil, 1988).

Esse "salvo nos casos previstos em lei" adapta-se perfeitamente às exigências constitucionais do artigo 209 da Lei Maior, explicitado no artigo 7 da LDB e em outras dimensões da normatização legal.

Assim, a autorização de funcionamento das instituições de ensino de caráter privado, para efeito da oferta dos serviços de educação escolar, con- 
siste em ato administrativo vinculado, espécie de delegação de serviço público (Barbosa, 1947, p. 31) próprio do Estado. A coexistência assinalada no artigo 206 da Constituição torna-se relativa ao cerne da titularidade do exercício da função de ensinar. O Estado tem a titularidade plena e o exercício pleno. Já a iniciativa privada possui uma titularidade compartilhada mediante condições, entre as quais a autorização e a avaliação de qualidade, de acordo com o artigo 209.

Como afirma Oswaldo Bandeira de Mello, ao referir-se aos serviços públicos não privativos do Estado:

“Nesta última categoria ingressam os serviços que o Estado pode desempenhar, imprimindo-lhes regime de direito público, sem, entretanto, proscrever a livre iniciativa do ramo de atividades em que se inserem. Seria o caso dos serviços de educação e saúde, por exemplo. Aos particulares é lícito desempenhá-los, independentemente de concessão" (Bandeira de Mello, 1969, p. 315).

O mesmo autor acrescenta:

“(...) a Carta Constitucional expressamente indica ser dever do Estado a prestação de serviços de ensino, saúde e previdência, o que não significa, entretanto, haja proscrito destas esferas a iniciativa privada. Por outro lado, a circunstância de deixar tal campo aberto aos particulares não autoriza a ilação de que, por tal motivo, estarão descaracterizados da categoria de serviço público, quando prestados pelo Estado sob regime peculiar, uma vez que seu desempenho se constitui em um dever para o Poder Público"' (Bandeira de Mello, 1969, p. 315).

O próprio Supremo Tribunal Federal já tem posição firmada a esse respeito. Ao interpretar o parágrafo $6^{\circ}$ do artigo 37 da Constituição Federal, que assegura o direito de regresso a quem for vítima de dolo por parte de pessoas jurídicas de direito público ou de direito privado, prestadoras de serviços públicos, diz:

“A obrigação governamental de preservar a intangibilidade dos alunos enquanto estes se encontrarem no recinto do estabelecimento escolar, constitui encargo indissociável do dever que incumbe ao Estado de dispensar proteção efetiva a todos os estudantes que se acharem sob a guarda imediata do Poder Público nos estabelecimentos oficiais de ensino" (Brasil, 1996a).

O ensino privado é, pois, um serviço público (impróprio) autorizado e cuja conseqüência maior - aliás, posta em lei - é o respeito às normas gerais da educação e a avaliação de qualidade, de acordo com o artigo 209 da Constituição e artigo 7 da LDB. Desta forma, o poder público cre- 
dencia os executores deste bem, autorizando-os e exercendo adequada fiscalização sobre eles.

Contudo, a Constituição Federal subdividiu as escolas privadas. Há aquelas que, embora devendo prestar um serviço de interesse público (direito ao saber), fazem-no através de mecanismos próprios do sistema contratual de mercado. São as 'escolas privadas lucrativas'. Trata-se de figura nova no âmbito do ensino superior, já que anteriormente este nível da educação nacional não poderia ter finalidade lucrativa ${ }^{3}$.

Este foi o entendimento doutrinário do Conselho Federal de Educação, nos anos 70 , como pode ser visto no parecer $\mathrm{n}^{\circ}$ 780/79, do conselheiro Caio Tácito:

\begin{abstract}
“Tornou-se tradicional, na jurisprudência do Conselho, a afirmativa de que a atividade educacional deve ser, necessariamente, uma atividade não lucrativa. É certamente razoável, a concepção de que a educação e a cultura não são artigos de comércio, em que a perseguição do lucro é a finalidade legítima e precípua do empresário, sujeito às limitações legais ou administrativas cabíveis. Todavia, o conceito não se pode extremar a rigores do absolutismo, a ponto de tornar cada empreendimento de ensino superior um complexo de benemerência e liberalidade, senão mesmo de prodigalidade. Temos para nós que o assunto, em todos os seus graus, é um serviço de utilidade pública, cuja exploração, dependente de autorização estatal, deve ficar sujeita, em sua prestação, a rigoroso controle de disciplina, que não lhe permitia ares de mercancia" (MEC, 1979).
\end{abstract}

E há aquelas que, embora tenham mecanismos privados de oferta do direito ao saber, optam por serem 'não-lucrativas'. Por sua vez, estas escolas privadas não-lucrativas diferenciam-se entre si como comunitárias, confessionais e filantrópicas (LDB, artigo 20).

Ao controlarem sua lucratividade e submeterem-se às determinações específicas da normatização, podem receber verbas públicas $(\mathrm{CF} / 88$, artigo 213, e LDB, artigo 77) e estão isentas de determinados impostos ( $\mathrm{CF} / 88$, artigo 150, inciso VI, letra c). Seja para regulamentar a possibilidade constitucional de que escolas sem fins lucrativos possam receber recursos públicos, seja para se ter um referencial legal para este assunto, vale a pena conferir o decreto $\mathrm{n}^{\circ} 3.860 / 01$, de 9 de julho de 2001, sobretudo o capítulo II ${ }^{4}$.

O decreto constitui-se num ato explicitador da organização do ensino superior, já que abrange vários campos da administração desta atividade, tais como: classificação das instituições de ensino superior (capítulo I), das entidades mantenedoras (capítulo II), da organização acadêmica das instituições de ensino superior (IES), cuja classificação comporta um escalonamento que vai das escolas superiores isoladas, passando pelas faculdades, faculdades integradas, centros universitários, até as universidades. Descreve as principais características de cada escalão e sua ligação com o princípio 
da autonomia. Um artigo importante é o de número 15, que obriga todas as instituições de ensino superior a tornarem públicos seus critérios de seleção, suas condições de oferta e funcionamento e seus recursos humanos e respectiva qualificação.

Também um maior detalhamento da avaliação do ensino superior, tal como estabelece a lei $\mathrm{n}^{\circ}$ 9.131, de 1995, está apresentado no capítulo IV do mesmo decreto. Já os processos de autorização, credenciamento, recredenciamento de instituições de ensino superior, reconhecimento e renovação de cursos e seus respectivos requisitos de habilitação estão dispostos no capítulo V. Ao lado de procedimentos operacionais destes processos, os artigos 35 a 37 tratam das figuras de desativação de cursos e descredenciamento de instituições.

Contudo, a organização da educação escolar, sendo uma organização de natureza nacional, se faz sob a República Federativa do Brasil. Diferentemente da organização da saúde - um sistema unificado (SUS), ainda que descentralizado -, a educação tem um desenho diferente.

A Constituição Federal de 1988 reconhece o Brasil como uma República Federativa formada pela união indissolúvel de Estados, municípios e Distrito Federal (artigo 1). E, ao se estruturar assim, o faz sob o princípio da cooperação recíproca ${ }^{5}$. Percebe-se, pois, que ao invés de um sistema hierárquico ou dualista, comumente centralizado, a Constituição Federal montou um sistema de repartição de competências e atribuições legislativas entre os integrantes do sistema federativo, dentro de limites expressos, reconhecendo a dignidade e a autonomia próprias de cada um deles.

A Constituição faz uma escolha por um regime normativo e político, plural e descentralizado, onde se cruzam novos mecanismos de participação social com um modelo institucional cooperativo, que amplia o número de sujeitos políticos capazes de tomar decisões.

Para dar conta desse modelo federado e cooperativo, a Constituição compôs um ordenamento jurídico complexo no qual coexistem atribuições privativas, distribuídas para cada ente federativo; competências concorrentes entre os mesmos; competências comuns entre esses entes; e, ainda, a participação em atribuições privativas da União mediante delegação.

As competências privativas da União estão previstas, sobretudo, nos artigos 21 e 22 da Constituição Federal; as privativas dos Estados, no artigo 18, parágrafo $4^{\circ}$, e nas competências residuais não enumeradas no artigo 25 assim como nas listadas nos parágrafos $2^{\circ}$ e $3^{\circ}$ do mesmo artigo; e as privativas dos municípios são listadas no artigo 30, que contém matéria própria dos municípios.

Os sistemas de ensino, dentro desse modelo federativo, passaram a usufruir existência legal, ficando a sua organização e o seu modo de funcionamento sob a esfera da autonomia dos entes federativos, obedecendo às leis nacionais e ao princípio da colaboração recíproca. Além das Diretrizes e Ba- 
ses da Educação Nacional (CF/88, artigo 22, inciso XXIV), do Plano Nacional de Educação (artigo 214), e até mesmo por meio dele, cabe à União um papel redistributivo, supletivo e eqüalizador, com assistência técnica e financeira aos Estados, ao Distrito Federal e aos municípios, tal como disposto no artigo 211 , parágrafo $1^{\circ}$, da Constituição.

No artigo 24 da Constituição, figuram as competências concorrentes entre União, Estados e Distrito Federal. É preciso observar que, neste caso, trata-se de assuntos sobre os quais esses entes federativos podem legislar. O inciso IX diz serem matéria concorrente de todos eles educação, cultura, ensino e desporto.

Destaque-se também o que dizem os quatro parágrafos deste artigo para se entender a complexa lógica constitucional:

“§ $1^{\circ}$ No âmbito da legislação concorrente, a competência da União limitar-se-á a estabelecer normas gerais.

$\S 2^{\circ}$ A competência da União para legislar sobre normas gerais não exclui a competência suplementar dos Estados.

$\S 3^{\circ}$ Inexistindo lei federal sobre normas gerais, os Estados exercerão a competência legislativa plena, para atender a suas peculiaridades.

$\S 4^{\circ}$ A superveniência de lei federal sobre normas gerais suspende a eficácia da lei estadual, no que lhe for contrário" (Brasil, 1988).

Além de explicitar os dispositivos próprios da competência privativa da União, especialmente os contidos no artigo 9, a LDB estabeleceu as normas gerais para todos os sistemas de ensino, seus níveis e suas etapas. Logo, a eficácia de uma lei estadual, mesmo no interior de sua atribuição, fica suspensa quando ela for contrária às normas gerais estabelecidas pela União.

A LDB, apesar de sua flexibilidade, não deixou de pontuar características importantes da organização da educação superior. A flexibilidade não significa ausência de determinadas imposições, nem de parâmetros reguladores. Assim, pode-se verificar, por exemplo, como no título IV da lei, “Da educação superior", há parâmetros definidos para toda a organização deste nível de ensino. Veja-se como exemplo o número de dias do ano letivo de trabalho acadêmico efetivo e as garantias que o estudante deve ter, ao entrar em uma instituição de ensino superior, em saber seus direitos.

A LDB, ao explicitar as competências da União, diz em seu artigo 9, inciso VII, que ela "incumbir-se-á de baixar normas gerais sobre cursos de graduação e pós-graduação" (Brasil, 1996b). E é no parágrafo $1^{\circ}$ deste artigo que se aponta o Conselho Nacional de Educação (CNE), cujas funções incluem o normatizar e o interpretar a legislação educacional.

Ao se reconhecer o que está posto nos artigos 8 e 9 da LDB, é preciso associá-los à lei $\mathrm{n}^{\circ} 4.024$, de 1961, com a redação dada pela lei $\mathrm{n}^{\circ}$ 9.131/95, que diz, no artigo 7, que compete ao CNE: 
“b) manifestar-se sobre questões que abranjam mais de um nível ou modalidade de ensino; c) deliberar sobre medidas para aperfeiçoar os sistemas de ensino, especialmente no que diz respeito à integração dos seus diferentes níveis e modalidades; (...) f) analisar e emitir parecer sobre questões relativas à aplicação da legislação educacional, no que diz respeito à integração entre os diferentes níveis e modalidades de ensino" (Brasil, 1995b).

Ademais, o próprio artigo 53, inciso V, da LDB fala também em 'diretrizes gerais pertinentes'. Ora, a quem cabe a definição de tais diretrizes?

A lei $n^{\circ}$ 9.131/95 (re)criou o CNE após a extinção do Conselho Federal de Educação em 1994. Esta lei deu nova redação a uns poucos artigos mantidos no que restou da lei $n^{\circ} 4.024 / 61$. Esta última também foi explicitamente reconhecida no artigo 92 da LDB.

A lei diz, no seu artigo 9, que caberá à Câmara de Educação Superior do Conselho Nacional de Educação (CES/CNE), entre outras atribuições,

“(...) analisar e emitir parecer sobre os resultados dos processos de avaliação da educação superior; $(. .$.$) c) deliberar sobre as diretrizes curriculares propostas pelo$ Ministério da Educação e do Desporto, para os cursos de Graduação; (...) e) deliberar sobre a autorização, o credenciamento e o recredenciamento periódico das instituições de educação superior, inclusive de universidades, com base em relatórios e avaliações apresentados pelo Ministério da Educação e do Desporto; f) deliberar sobre os estatutos das universidades e o regimento das demais instituições de educação superior que fazem parte do sistema federal de ensino" (Brasil, 1995b).

Além de ter sido explicitamente recebida pela LDB no artigo 92, o teor da lei $n^{\circ}$ 9.131/95 foi reconfirmado também nos artigos 8 e 9 daquela lei.

Face à normatização da educação nacional, portanto, o CNE tem competência para baixar resoluções que visem ao aperfeiçoamento da educação nacional. É preciso interpretar quando tais resoluções voltam-se para o conjunto da educação nacional e quando elas se dirigem apenas ao sistema federal de ensino.

Tal distinção é fundamental na medida em que o sistema federativo de repartição de competências por cooperação recíproca deve ser respeitado.

A nossa Constituição Federal, ao invés de associar o adjetivo nacional ou único a sistema de ensino - como faz com o sistema financeiro nacional, o sistema nacional de emprego e o sistema único de saúde - opta por 'pluralizar os sistemas' (artigo 211), cuja articulação mútua será organizada por meio de uma engenharia consociativa e articulada com normas e finalidades gerais, através de competências privativas, concorrentes e comuns. É desta concepção articulada entre os sistemas que decorre a exigência de um financiamento vinculado aos impostos na própria Constituição ${ }^{6}$ e de um Plano 
Nacional de Educação (artigo 214) que seja, ao mesmo tempo, racional nas metas e meios e efetivo nos seus fins.

A lógica do modelo constitucional vigente e da LDB presume a inexistência de incompatibilidades reais ou supostas, seja pela repartição de atribuições, seja pelo princípio de colaboração, seja pelas finalidades comuns. Qualquer invasão de competências toma, então, um caráter anticonstitucional.

Nesse sentido, tanto a Constituição como a LDB insistem no princípio da colaboração recíproca como o horizonte no qual os entes federativos, todos autônomos nos termos desta Constituição (artigo 18), devem trabalhar entre si e gerir o sistema complexo em que vicejam as múltiplas competências: exclusivas, privativas, concorrentes e comuns. As gestões a serem feitas e as dificuldades e os problemas a serem resolvidos implicam, pois, além do respeito às normas gerais, a descentralização e a repartição de competências. O federalismo constitucional é complexo e sua efetivação o é igualmente. A colaboração recíproca pressupõe o diálogo como método e a democratização como meta.

Por isso, "os Estados organizam-se e regem-se pelas Constituições e leis que adotarem" (artigo 25) e “o Município reger-se-á por lei orgânica” (artigo 29), atendidos, em ambos os casos, os princípios estabelecidos na Constituição.

Coerente com estes artigos, e com o 211, o artigo 10 da LDB deixa claro que

“Os Estados incumbir-se-ão de: I - organizar, manter e desenvolver os órgãos e instituições oficiais dos seus sistemas de ensino; (...) IV - autorizar, reconhecer, credenciar, supervisionar e avaliar, respectivamente, os cursos das instituições de educação superior e os estabelecimentos do seu sistema de ensino; V - baixar normas complementares para o seu sistema de ensino" (Brasil, 1996b).

Portanto, dentro de suas competências, os Estados podem exercer sua função concorrente também no ensino superior.

Disso tudo decorre que a distribuição de competências, face aos objetivos maiores da educação escolar, deve ser feita 'diferencialmente' dentro do âmbito de aplicabilidade de cada ente federativo, e 'compartilhadamente' por meio do regime de colaboração, próprio do novo caráter da federação brasileira. Assim, as relações interfederativas não se dão mais por processos hierárquicos e sim por meio do respeito aos campos próprios das competências assinaladas, mediadas e articuladas pelo princípio da colaboração recíproca e dialogal e pelo respeito às normas gerais da educação nacional.

Contudo, apesar da Constituição (que é de 1988) determinar que o regime de colaboração fosse objeto de uma lei complementar, até hoje o Congresso Nacional não se debruçou sobre essa matéria... ${ }^{7}$ 


\section{O papel do Estado}

Voltando-se agora para a face pública do ensino, é preciso constatar que os governos têm proclamado o esgotamento de sua capacidade financeira para bancar a expansão da sua rede de ensino superior. Os governos estão interessados é em 'otimizar' e 'racionalizar' seus gastos. Pode-se falar em uma contenção no que concerne ao crescimento da rede física e em uma crise, posta pelo financiamento, no que se refere aos rumos das funções clássicas da educação. Dessa omissão do Estado, especialmente no ensino superior, associada à demanda reprimida, é que o privado, sob o sistema contratual de mercado, ocupará os espaços abertos pela ausência estatal.

Num país com imensas disparidades regionais, o papel redistributivo da União lhe obriga a tornar o equilíbrio federativo mais equânime. Num país em que a reforma tributária é sempre razão para enormes polêmicas, o caráter supletivo da União, especialmente nas competências materiais comuns, é indispensável. Redistribuição e suplementação concorrem para uma educação menos injusta e mais igualitária. No caso do ensino superior universitário, talvez fosse este o objetivo da redação do artigo 60 do Ato das Disposições Constitucionais Transitórias da Constituição, antes da redação dada pela emenda $n^{\circ} 14$, de 1996. O artigo, em sua versão original, dizia no parágrafo único:

“Em igual prazo [isto é, nos dez primeiros anos da promulgação da Constituição] as universidades públicas descentralizarão suas atividades, de modo a estender suas unidades de ensino superior às cidades de maior densidade populacional" (Brasil, 1988).

Este parágrafo único - seja por conta da interpretação ambivalente do caput do artigo, seja por conta de um progressivo afastamento, por parte da União, das responsabilidades do ensino superior público - foi simplesmente eliminado da emenda constitucional $n^{\circ} 14 / 96$, mais conhecida como emenda do Fundef (Fundo de Manutenção e Desenvolvimento do Ensino Fundamental e de Valorização do Magistério).

Assim, se crescimento houver dentro dos sistemas públicos, será através do aproveitamento mais intensivo e extensivo da capacidade já instalada. Desse modo, nada indica uma expansão da rede física dos estabelecimentos públicos de ensino superior que seja maior que um crescimento residual ou marginal. Por outro lado, a exoneração do poder público face à manutenção adequada do patrimônio construído pode significar um desmantelamento de um sistema de pesquisa básica e a perda de uma tradição de referência qualitativa. A ausência de uma pesquisa permanente e de uma oferta de cursos pouco colados ao mercado são motivos de preocupação. É o conjunto 
do ensino superior, e com isso a própria nação, que perde com a asfixia da universidade pública.

Por seu turno, é notável a expansão do ensino superior privado especialmente a partir do segundo semestre de 1997. Se naquele ano todo o setor público contava com 760 mil matrículas (39\%) e todo o setor privado com 1,2 milhão (61\%), em 2001 o segmento público subia para 940 mil matrículas $(31 \%)$, enquanto o privado ascendia para 2,1 milhões $(69 \%)^{8}$.

Essa expansão avultada, apesar de tudo, é ainda reduzida face à pressão dos concluintes do ensino médio. São mais de 4,5 milhões de candidatos para perto de 1,4 milhão de vagas. Contudo o segmento público só oferece 270 mil vagas para os mais de 2,5 milhões de candidatos que o procuram.

Embora não se pretenda focar a perspectiva social, nunca é demais recordar que o acesso, desde que se conhece o ensino superior no país, encontra barreiras sociais postas por uma formação social elitista e discriminatória que privilegia destinatários provindos dos estratos sociais abastados. Além disso, esse nível da educação nacional conhece as barreiras de uma histórica secundarização do ensino fundamental, recentemente enfrentada. As conseqüências dessas barreiras determinaram um ensino superior elitizado, não apoiado nem na igualdade de oportunidades, nem na eqüidade social, mas em privilégios de ordem sócio-econômica.

Por outro lado, já há múltiplos estudos sociológicos, inclusive com dados de ordem estatística, que apontam para o jogo oscilante entre tempos de crescimento e de freio de instituições e matrículas. Sabe-se, por exemplo, que a década de 1970 favoreceu a expansão das instituições privadas de ensino superior com caráter não universitário. Sabe-se também que o Estado Federal praticamente ficou estagnado no que se refere à expansão de sua rede de ensino superior.

O crescimento do ensino superior hoje, para dar conta da demanda que continua reprimida, seguirá, tendencialmente, o caminho já anteriormente percorrido.

\section{Conclusão}

Sem ignorar, pois, o caráter discriminatório dessas barreiras, sem deixar de considerar a trama mais ou menos expansiva dos diferentes momentos das décadas passadas, este texto pretendeu 'enfocar' o tema proposto através da dimensão política com ênfase em aspectos normativos da legislação, condicionadores da evolução da organização do ensino.

É nesse sentido que a avaliação talvez seja a mais profunda ruptura estabelecida na atual organização da educação nacional. Ela entra na Constituição e de certo modo substitui o conceito de concessão. A avaliação ainda 
não se constitui como uma cultura, o que exigiria processos mais permanentes e consolidados. Contudo pode-se dizer que ela já foi acolhida como princípio e tem demonstrado seu peso na busca de maior legitimidade por parte das instituições.

A LDB avança e explicita essa ruptura estabelecendo critérios mais flexíveis no processo de abertura de entidade educacional, pública ou privada. Ainda que mantida a autorização, a avaliação é uma espécie de contrapartida da flexibilização. Através dela entra em cena a variável 'qualidade', cuja mensuração não pode ficar confinada apenas ao poder autorizatório do poder público e ao grau de impacto aferido pelo mercado.

A avaliação terá, cada vez mais, um impacto sobre a organização da educação nacional. Ela será como um termômetro para possibilitar a qualidade necessária para que essa organização, seja no setor público, seja no setor privado, alcance os objetivos maiores da educação superior ${ }^{9}$.

Conclui-se este texto com um trecho extraído do Plano Nacional de Educação:

“As instituições públicas deste nível de ensino não podem prescindir do apoio do Estado. As universidades públicas têm importante papel a desempenhar no sistema, seja na pesquisa básica e na pós-graduação stricto sensu, seja como padrão de referência no ensino da graduação. Além disso, cabe-lhe qualificar os docentes que atuam na educação básica e os docentes da educação superior" (Brasil, 2001).

Padrão de referência não quer dizer superior em termos hierárquicos. Quer dizer simplesmente que as instituições públicas, por sua tradição, por sua natureza e por sua distância com relação ao sistema contratual de mercado, devem representar, na organização da educação nacional, o horizonte maior de possibilidades qualitativas para a aspiração de um país independente, desenvolvido e democrático.

\section{Notas}

1 Professor emérito da Universidade Federal de Minas Gerais (UFMG) e do Programa de Pós-Graduação em Educação da Pontifícia Universidade Católica de Minas Gerais (PUCMG). Doutor em Educação pela Pontifícia Universidade Católica de São Paulo (PUC-SP). $<$ crjcury.bh@terra.com.br>

2 Não é por acaso que educação e saúde comparecem no artigo 6 da Constituição Federal de 1988 como direitos sociais solenemente proclamados. 
3 Ver resolução n ${ }^{\circ}$ 29/74 e parecer n ${ }^{\circ}$ 780/79 do Conselho Federal de Educação.

4 Nesse sentido, o atual anteprojeto governamental de lei de Reforma Universitária avança em relação ao decreto $\mathrm{n}^{\circ} 3.860 / 01$, estabelecendo um marco regulatório para as instituições privadas de ensino.

${ }^{5}$ Como demonstram os artigos $1,18,23$ e 60, parágrafo $4^{\circ}$, inciso I.

${ }^{6}$ Essa é uma outra semelhança entre as áreas da educação e da saúde. Ambas têm vinculação obrigatória na Constituição, embora com perfis diferentes.

7 Para alguns, a Lei de Responsabilidade Fiscal seria o suporte desse regime. O governo acaba de enviar projeto de emenda constitucional (EC) estabelecendo uma espécie de regime de colaboração por meio de um fundo financeiro relativo à educação básica (Fundeb), como o governo passado fizera com o ensino fundamental (Fundef). Esse projeto de EC foi aprovado em primeiro turno no dia 24 de janeiro de 2006 na Câmara dos Deputados. $\mathrm{O}$ atual anteprojeto de Reforma Universitária estabelece, como para o Fundef - e, se vingar, também para o Fundeb -, um sistema de subvinculação dos recursos constitucionalmente voltados para a educação.

8 Os números foram arredondados e visam apenas a dar uma idéia de grandeza da expansão. Os dados exatos encontram-se em MEC (2002).

${ }^{9}$ Nesse sentido, o atual governo, por meio de lei, criou o Sistema Nacional de Avaliação do Ensino Superior (Sinaes) que avança significativamente em relação ao anterior sistema denominado Provão.

\section{Referências}

BANDEIRA DE MELLO, Oswaldo A. 1969. Princípios gerais do direito administrativo. São Paulo: Forense.

BANDEIRA DE MELLO, Celso Antônio. 1996. Curso de direito administrativo. São Paulo: Malheiros.

BARBOSA, Rui. 1947. Reforma do ensino primário e várias instituições complementares da instrução pública. Rio de Janeiro: Ministério da Educação e Saúde. (Obras completas; v. 10).

BRASIL. 1988. Constituição da República Federativa do Brasil.

.1995a. Lei no. 8.987, de 13 de fevereiro de 1995. Dispõe sobre o regime de concessão e permissão da prestação de serviços públicos previsto no art. 175 da Constituição Federal, e dá outras providências.

.1995b. Lei no. 9.131, de 24 de novembro de 1995. Altera dispositivos da lei no. 4.024, de 20 de dezembro de 1961, e dá outras providências.

.Supremo Tribunal Federal. 1996a. Recurso Especial no. 109.615-2-RJ, de 02 de agosto de 1996.

.1996b. Lei no. 9.394, de 20 de dezembro de 1996. Estabelece as Diretrizes e Bases da Educação Nacional.

2001. Lei no. 10.172 , de 09 de janeiro de 2001. Aprova o Plano Nacional de Educação e dá outras providências.

CURY, Carlos Roberto J. 1992. O público e o privado na educação brasileira contem- 
porânea: posições e tendências. Cadernos de Pesquisa, n. 81, p. 33-44.

DI PIETRO, Maria Sylvia Z. 2004. Direito administrativo. São Paulo: Atlas.

MEC (Ministério da Educação). Conselho Federal de Educação. 1979. Parecer no. 780, de 04 de junho de 1979. Dispõe sobre entidade mantenedora e prestação de serviços à entidade mantida. .2002. Sinopse estatística da educação superior-2001 (Censo da Educação Superior 2001). Brasília: Instituto Nacional de Estudos e Pesquisas Educacionais Anísio Teixeira (Inep).

MEIRELLES, Hely L. 1993. Direito administrativo brasileiro. São Paulo: Malheiros.

SILVA, De Plácido e. 1991. Vocabulário jurídico. Rio de Janeiro: Forense.

SILVA, José Afonso da. 1999. Curso de direito constitucional positivo. São Paulo: Malheiros. 